\title{
The Effect of Continuous Light Exposure of Rats on Cardiac Response to Ischemia-Reperfusion and NO-Synthase Activity
}

\author{
R. VAŽAN ${ }^{1,2}$, P. JANEGA ${ }^{3,4}$, S. HOJNÁ ${ }^{5}$, J. ZICHA ${ }^{5}$, F. ŠIMKO ${ }^{6}$, \\ O. PECHÁŇOVÁ ${ }^{3,5}, J_{\text {. STYK }}^{2}$, L. PAULIS ${ }^{3,5,6}$
}

${ }^{1}$ Department of Physiology, School of Medicine, Comenius University, Bratislava, Slovak Republic, ${ }^{2}$ Institute for Heart Research, Slovak Academy of Sciences, Bratislava, Slovak Republic, ${ }^{3}$ Institute of Normal and Pathological Physiology, Slovak Academy of Sciences, Bratislava, Slovak Republic, ${ }^{4}$ Department of Pathology, School of Medicine, Comenius University, Bratislava, Slovak Republic, ${ }^{5}$ Institute of Physiology and Centre for Cardiovascular Research, Academy of Sciences of the Czech Republic, Prague, Czech Republic, ${ }^{6}$ Institute of Pathophysiology, School of Medicine, Comenius University, Bratislava, Slovak Republic

Received July 4, 2007

Accepted August 28, 2007

On-line available September 5, 2007

\begin{abstract}
Summary
Factors modulating cardiac susceptibility to ischemia-reperfusion (I/R) are permannetly attracting the attention of experimental cardiology research. We investigated, whether continuous $24 \mathrm{~h} /$ day light exposure of rats can modify cardiac response to I/R, NO-synthase (NOS) activity and the level of oxidative load represented by conjugated dienes (CD) concentration. Two groups of male adult Wistar rats were studied: controls exposed to normal light/dark cycle (12 h/day light, $12 \mathrm{~h} /$ day dark) and rats exposed to continuous light for 4 weeks. Perfused isolated hearts (Langendorff technique) were exposed to $25 \mathrm{~min}$ global ischemia and subsequent $30 \mathrm{~min}$ reperfusion. The recovery of functional parameters (coronary flow, left ventricular developed pressure, contractility and relaxation index) during reperfusion as well as the incidence, severity and duration of arrhythmias during first $10 \mathrm{~min}$ of reperfusion were determined. The hearts from rats exposed to continuous light showed more rapid recovery of functional parameters but higher incidence, duration and severity of reperfusion arrhythmias compared to controls. In the left ventricle, the NOS activity was attenuated, but the $\mathrm{CD}$ concentration was not significantly changed. We conclude that the exposure of rats to continuous light modified cardiac response to I/R. This effect could be at least partially mediated by attenuated NO production.
\end{abstract}

Key words

Heart $\bullet$ Melatonin $\bullet$ Reperfusion injury $\bullet$ Nitric oxide synthase $\bullet$ Free radicals

\section{Introduction}

The ischemic heart disease is one of the leading causes of morbidity and mortality in developed countries
(Leaf and Kang 1996). The pathophysiological mechanism of ischemia-reperfusion injury is involved in the development of myocardial infarction and cardiac arrhythmias that are the most serious manifestations of 
this disease. Therefore, mechanisms modulating myocardial response to ischemia-reperfusion remain to be a hot topic of experimental cardiology.

Several studies have demonstrated that continuous light exposure influences the cardiovascular system (Briaud et al. 2004) and abolishes nocturnal rise of melatonin blood levels (Brown et al. 1991). This "functional pinealectomy" represents a more physiological model of reduced melatonin levels as compared to surgical pinealectomy (removal of epiphysis), which decreases not only the night-time melatonin level but also the day-time melatonin level (Brown et al. 1991). Surgical pinealectomy temporarily increases blood pressure (Zanoboni and ZanoboniMuciaccia 1967) and induces myocardial fibrosis (Mizrak et al. 2004). Deficient melatonin production may result in the lack of antioxidant action of melatonin (Girouard et al. 2004) and impairment of endothelial NO production, which was suggested to be enhanced by chronic melatonin treatment (Šimko and Paulis 2007).

In the present study, we investigated whether four-week exposure of experimental rats to continuous light can modify cardiac response to ischemia-reperfusion and modulate cardiac NO-synthase (NOS) activity or oxidative load, expressed by the concentration of conjugated dienes (CD).

\section{Materials and Methods}

\section{Experimental animals}

The experiments were performed on adult male Wistar rats (body weight 250-320 g), in accordance with the Guide for the Care and Use of Laboratory Animals published by the US National Institutes of Health (NIH publication No. 85-23, revised 1996). Rats were housed under standard laboratory conditions and fed with standard pellet diet and tap water ad libitum. The room for rats was windowless with automatic regulation of light/dark cycle. Controls were housed under standard (12 h/day light, $12 \mathrm{~h} /$ day dark) day cycle and animals exposed to continuous light under $24 \mathrm{~h}$ /day light (450 lux) for 4 weeks.

\section{Perfusion of the hearts}

The animals ( $\mathrm{n}=11$ in each group) were anesthetized with pentobarbitone sodium $(60 \mathrm{mg} / \mathrm{kg}$ b.w. i.p.) and treated with heparin (500 IU i.p.). Then the hearts were excised, immersed into physiological saline solution $\left(4{ }^{\circ} \mathrm{C}\right)$ and subsequently retrogradely perfused with Krebs-Henseleit solution (in mmol/1: $118.0 \mathrm{NaCl}$, $3.2 \mathrm{KCl}, 1.2 \mathrm{MgSO}_{4}, 25.0 \mathrm{NaHCO}_{3}, 1.18 \mathrm{KH}_{2} \mathrm{PO}_{4}, 2.5$ $\mathrm{CaCl}_{2}$ and 11.1 glucose, pH $7.4,37^{\circ} \mathrm{C}$, oxygenated carbogen - $95 \% \mathrm{O}_{2}, 5 \% \mathrm{CO}_{2}$ ) at a constant perfusion pressure $75 \mathrm{~mm} \mathrm{Hg}$ (Langendorff technique). A waterfilled non-elastic balloon, coupled to a pressure transducer (MLP844, ADInstruments), was inserted into the left ventricular cavity via an incision in the left atrium. Diastolic pressure was adjusted to 5-7 $\mathrm{mm} \mathrm{Hg}$. For epicardial electrogram recording and stimulation, an electrode was attached to the apex of the heart. Data were continuously recorded on PC using PowerLab Chart 5 (ADInstruments Ltd, Bella Vista, Australia).

The perfusion protocol consisted of $20 \mathrm{~min}$ standard perfusion (stabilization) and $25 \mathrm{~min}$ global normothermic ischemia followed by $30 \mathrm{~min}$ reperfusion. Electrical stimulation (300 bpm) was used except of the duration of ischemia and the first $10 \mathrm{~min}$ of reperfusion, when reperfusion arrhythmias were determined.

\section{Analysis of reperfusion arrhythmias}

Reperfusion arrhythmias in the first 10 minutes of reperfusion were evaluated using the Lambeth Conventions (Walker et al. 1988). The incidence and the summary duration of severe reperfusion arrhythmias (ventricular tachycardia, VT, ventricular fibrillation, VF and sustained ventricular fibrillation lasting more than 2 min, SVF) were determined. The arrhythmia score was evaluated on the base of the most sever arrhythmia occurred (1 - single premature ventricular complexes, 2 - salvos, 3 - VT (4 or more consecutive premature ventricular complexes), $4-$ reversible VF and 5 - sustained VF).

\section{Analysis of functional parameters}

Coronary flow (CF), left ventricular systolic pressure (LVSP), left ventricular diastolic pressure (LVDP), $+\mathrm{dP} / \mathrm{dt} \max$ (contractility index), $-\mathrm{dP} / \mathrm{dt} \max$ (relaxation index) and left ventricular developed pressure (LVDevP, the difference between LVSP and LVDP) were determined.

Post-ischemic values of functional parameters (from the 15th, 20th, 25th and 30th min of reperfusion) were expressed as percentage of the baseline preischemic values of these parameters, measured during the 30th min of stabilization.

\section{Conjugated dienes concentration}

Samples from left ventricles ( $\mathrm{n}=8$ in each group) 
were homogenized in $15 \mathrm{mmol} / \mathrm{l}$ EDTA containing $4 \%$ $\mathrm{NaCl}$. Lipids were extracted using 1:1 chloroformmethanol mixture. The concentration of $\mathrm{CD}$ was estimated as described by Kogure et al. (1982). Chloroform was evaporated in $\mathrm{N}_{2}$ atmosphere. After the addition of $3 \mathrm{ml}$ cyclohexane the absorbance at $233 \mathrm{~nm}$ (GBC UV/VIS 911 A) was determined. The amount of $\mathrm{CD}$ was calculated using the extinction coefficient $\varepsilon=$ $29000 \mathrm{l} / \mathrm{mol} / \mathrm{cm}$ and expressed as $\mu \mathrm{mol}$ per $\mathrm{g}$ tissue.

\section{NO-synthase activity assay}

Total NOS activity was determined in crude tissue homogenates of the left ventricles $(n=6$ in each group) by measuring the formation of $\left[{ }^{3} \mathrm{H}\right]$-citrulline from $\left[{ }^{3} \mathrm{H}\right]$-L-arginine (Amersham International plc, UK) (Bredt and Snyder 1990), with some modifications (Bernátová et al. 1999). In short, $20 \%$ homogenates were centrifuged $20 \mathrm{~min}$ at $13000 \mathrm{~g} .50 \mu \mathrm{l}$ of supernatant was incubated in the presence of $50 \mu \mathrm{l}$ reaction agent $(0.1 \mathrm{~mol} / 1 \mathrm{Tris}-\mathrm{HCl}$, pH 7.4; 2 mmol/1 Ca ${ }^{2+} ; 10 \mu \mathrm{mol} / 1$ FAD:FMN, 1:1; $30 \mathrm{nmol} / 1$ calmodulin; $1 \mathrm{mmol} / 1 \quad \beta$-NADPH; $500 \mu \mathrm{mol} / 1$ tetrahydrobiopterine; $2 \mu \mathrm{mol} / 1 \mathrm{~L}$-arginine and $2 \mu \mathrm{l}\left[{ }^{3} \mathrm{H}\right]$ L-arginine (specific activity $5 \mathrm{GBq} / \mathrm{mmol}, 100000 \mathrm{dpm}$ ). After $30 \mathrm{~min}$ incubation at $37{ }^{\circ} \mathrm{C}$, the reaction was stopped by addition of $1 \mathrm{ml}$ ice-cold stop agent (0.02 mol/1 HEPES, pH 5.5; 2 mmol/1 EDTA, 2 mmol/1 EGTA, $1 \mathrm{mmol} / 1 \mathrm{~L}$-citruline). $1 \mathrm{ml}$ of reaction products was applied to Dowex 50 WX-8 columns $\left(\mathrm{Na}^{+}\right.$form). $\left[{ }^{3} \mathrm{H}\right]$-citruline content was measured by liquid scintillation counting (TriCarb, Packard, UK). NOS activity was expressed as picokatal per gram of protein (pkat/g protein).

\section{Statistics}

Data are presented as means \pm standard error of mean (SEM). Results were considered significant if $\mathrm{p}<0.05$. Two-tailed unpaired Student t-test for normally distributed values and Mann-Whitney U-test for values not normally distributed was used. Normality of distribution was tested according to Kolmogorov and Smirnov and the difference in standard deviations was tested by Barlett's test.

\section{Results}

\section{Heart weight and body weight}

Heart weight of control rats was $0.88 \pm 0.02 \mathrm{~g}$, the exposure of rats to continuous light increased heart weight by $24 \%(p<0.05)$. Body weight of control rats
Table 1. Pre-ischemic values of functional parameters.

\section{Controls Light}

\begin{tabular}{|c|c|c|}
\hline \multicolumn{3}{|l|}{$C F$} \\
\hline$(\mathrm{ml} / \mathrm{min})$ & $9.23 \pm 0.73$ & $9.36 \pm 0.63$ \\
\hline \multicolumn{3}{|l|}{ LVDevP } \\
\hline$(\mathrm{mmHg})$ & $87.07 \pm 5.47$ & $80.18 \pm 4.36$ \\
\hline \multicolumn{3}{|l|}{$+d P / d t \max$} \\
\hline$(\mathrm{mmHg} / \mathrm{s})$ & $3876 \pm 277$ & $3687 \pm 196$ \\
\hline \multicolumn{3}{|l|}{$-d P / d t \max$} \\
\hline$(\mathrm{mmHg} / \mathrm{s})$ & $1956 \pm 193$ & $1759 \pm 188$ \\
\hline
\end{tabular}

Data are means \pm SEM, CF, coronary flow, LVDevP, left ventricular developed pressure, +dP/dt max, contractility index, $\mathrm{dP} / \mathrm{dt}$ max, relaxation index.

was $264 \pm 3.5 \mathrm{~g}$, the exposure of rats to continuous light increased body weight by $23 \%(\mathrm{p}<0.05)$. The relative heart weight (heart weight/body weight) was $3.34 \pm 0.05$ $\mathrm{g} / \mathrm{kg}$ in controls and the exposure of rats to continuous light had no significant effect on the relative heart weight.

\section{Preischemic values of functional parameters}

There were no significant differences between the groups in the functional cardiovascular parameters (coronary flow, left ventricular developed pressure, contractility index and relaxation index) at the end of stabilization (Table 1).

\section{Recovery of functional parameters during reperfusion}

During reperfusion the course of recovery of all investigated functional parameters: coronary flow (Fig. 1A), left ventricular developed pressure (Fig. 1B), contractility index (Fig. 2A) and relaxation index (Fig. 2B) was significantly improved in the hearts from rats exposed to continuous light.

\section{Reperfusion arrhythmias}

The incidence (Fig. 3A) and total duration of severe reperfusion arrhythmias (VT, VF, SVF) (Fig. 3B), as well as the arrhythmia score (Fig. 4) was significantly higher in the hearts from rats exposed to continuous light in comparison to hearts from control rats.

\section{Conjugated dienes concentration}

In the control group the $\mathrm{CD}$ concentration in the left ventricle was $1.31 \pm 0.16 \mu \mathrm{mol} / \mathrm{g}$ of left ventricular tissue. Continuous light exposure of rats caused a non- 
$\mathbf{A}$

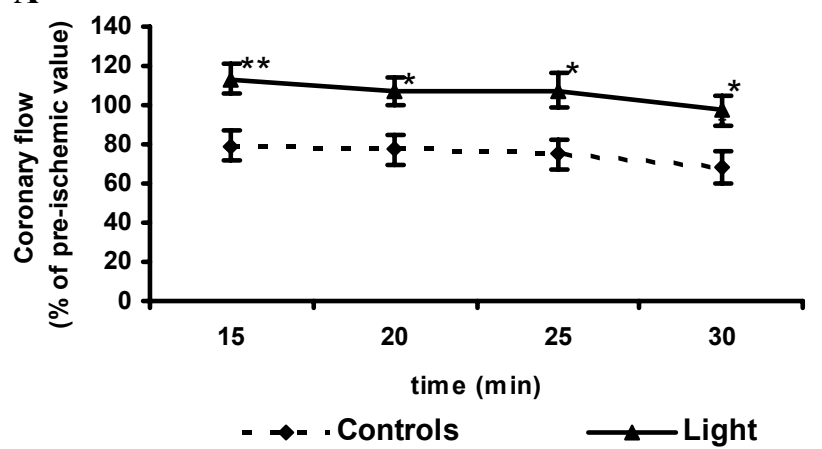

B

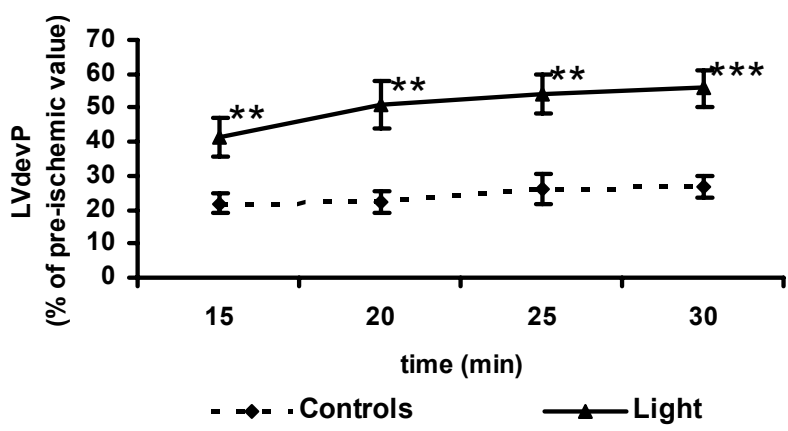

Fig. 1. Recovery of coronary flow (A) and left ventricular developed pressure, LVdevP (B) during reperfusion in controls and rats exposed to continuous light (light) for 4 weeks. Data are means \pm SEM. $* \mathrm{p}<0.05, * * \mathrm{p}<0.01, * * * \mathrm{p}<0.001$, Student t-test.

significant increase of $\mathrm{CD}$ concentration by $34 \%$ in the left ventricle (Fig. 5A).

\section{NO-synthase activity}

In the control group the NOS activity in the left ventricle was $11.50 \pm 1.44 \mathrm{pkat} / \mathrm{g}$ of protein. Continuous light exposure of rats caused decline in NOS activity in the left ventricle by $35 \%(\mathrm{p}<0.05)$ (Fig. $5 \mathrm{~B})$.

\section{Discussion}

We investigated the effect of 4-week continuous light exposure of experimental rats on cardiac response to ischemia-reperfusion, NOS activity and CD concentration. Although the hearts from light-exposed rats showed more rapid recovery of functional parameters, the incidence, total duration and severity of reperfusion arrhythmias were higher in this group. The cardiac NOS activity was attenuated, but the concentration of conjugated dienes was not significantly altered.

The surgical removal of epiphysis, pinealectomy, decreases both nocturnal and daily levels of melatonin (Brown et al. 1991) and is associated with



B

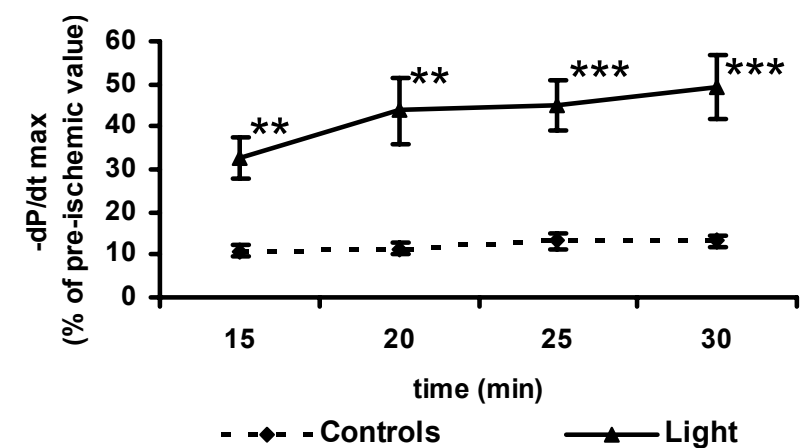

Fig. 2. Recovery of contractility index, $+d P / d t \max (\mathbf{A})$ and relaxation index, $-\mathrm{dP} / \mathrm{dt}$ min (B) during reperfusion in controls and rats exposed to continuous light (light) for 4 weeks. Data are means \pm SEM. $* * \mathrm{p}<0.01, * * * \mathrm{p}<0.001$, Student t-test.

temporary hypertension (Zanoboni and ZanoboniMuciaccia 1967), enhanced vasoconstriction (Cunnane et al. 1980) and increased incidence and prolonged duration of reperfusion arrhythmias (Sahna et al. 2002). The fact that hypertension induced by pinealectomy is reversible after exogenous melatonin administration suggests that it is at least partially mediated by the deficit of melatonin production after pinealectomy (Holmes and Sugden 1976). A different experimental model of decreased melatonin levels is the exposure of experimental animals to continuous light (Delibas et al. 2002, Briaud et al. 2004, Paulis et al. 2006). This "functional pinealectomy" abolishes the nocturnal rise of melatonin concentration, without influencing day-time levels of melatonin (Brown et al. 1991). Although this method for induction of melatonin deficit represents a slightly more physiological approach, the effect of functional pinealectomy on ischemia-reperfusion injury, cardiac NOS activity and oxidative load has yet, to our knowledge, not been investigated.

In our experiments on hearts isolated from rats exposed to continuous light for 4 weeks, we observed increased incidence and severity and prolonged duration of severe reperfusion arrhythmias, which is analogous to 

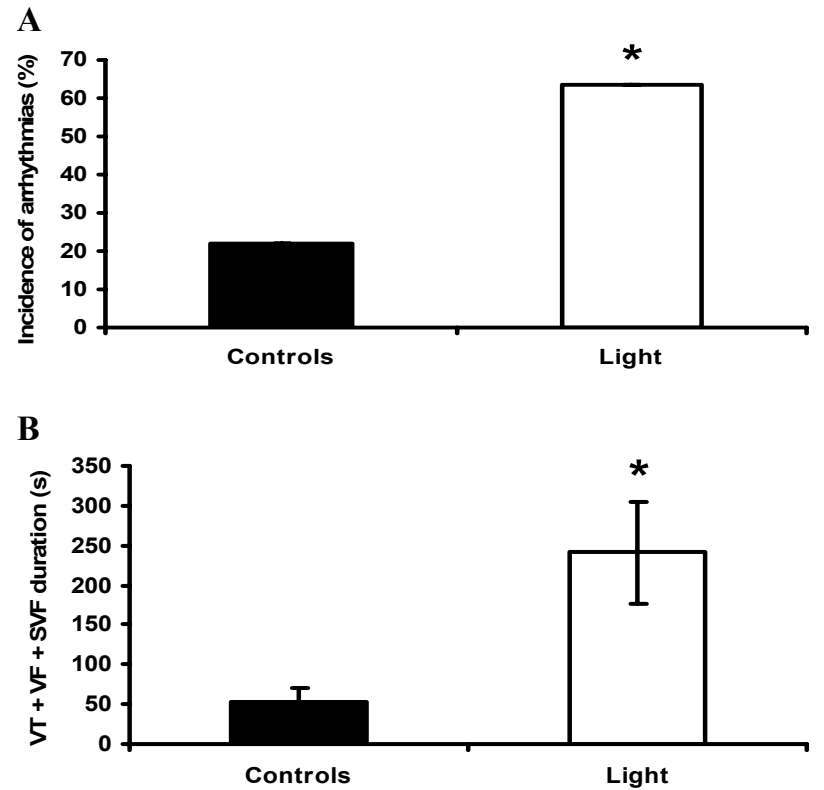

Fig. 3. The incidence (A) and summary duration (B) of severe reperfusion arrhythmias: ventricular tachycardia (VT), ventricular fibrillation (VF) and sustained ventricular fibrillation (SVF) in controls and rats exposed to continuous light (light) for 4 weeks. Data are means \pm SEM. $* p<0.05$, Student t-test.

the proarrhythmic effect of surgical pinealectomy (Sahna et al. 2002). However, at the same time the course of recovery of all investigated functional parameters (coronary flow, left ventricular developed pressure, contractility and relaxation index) during reperfusion was significantly improved. Having in mind the reported lower plasma levels of melatonin in light-exposed animals, these results are in agreement with impaired post-ischemic recovery of contractility and with lower incidence of arrhythmias after the addition of melatonin in high doses to the perfusion solution in ischemiareperfusion experiments (Važan et al. 2003).

Melatonin, whose level is decreased during the exposure of rats to continuous light, was reported to influence the major factors in the development of ischemia-reperfusion injury: the concentration of free radicals (Allegra et al. 2003, Reiter 2000) as well as the intracellular calcium homeostasis (Mei et al. 2001). Especially the increased antioxidant capacity of the heart was suggested to contribute to mitigating effect of melatonin on the size of infarct induced by I/R (Sahna et al. 2005).

In our study, the level of conjugated dienes, formed by membrane lipid peroxidation triggered by free radicals, was only non-significantly elevated after the exposure of rats to continuous light. On the other hand, continuous light attenuated the cardiac NOS activity. The

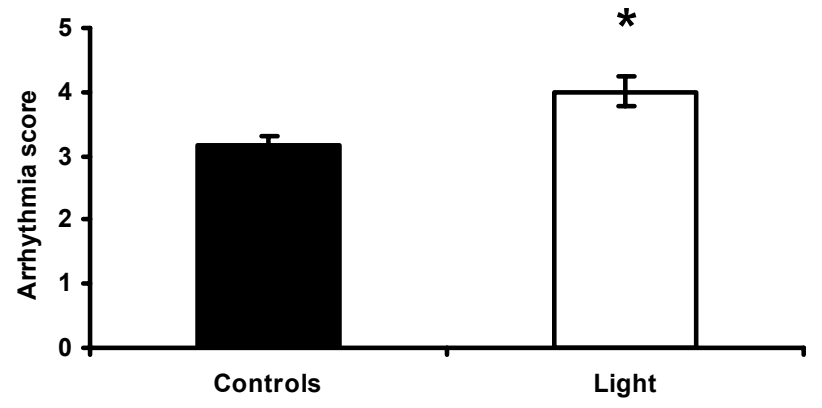

Fig. 4. The arrhythmia score of reperfusion arrhythmias in controls and rats exposed to continuous light (light) for 4 weeks. Data are means \pm SEM. ${ }^{*} p<0.05$, Mann-Whitney u-test.
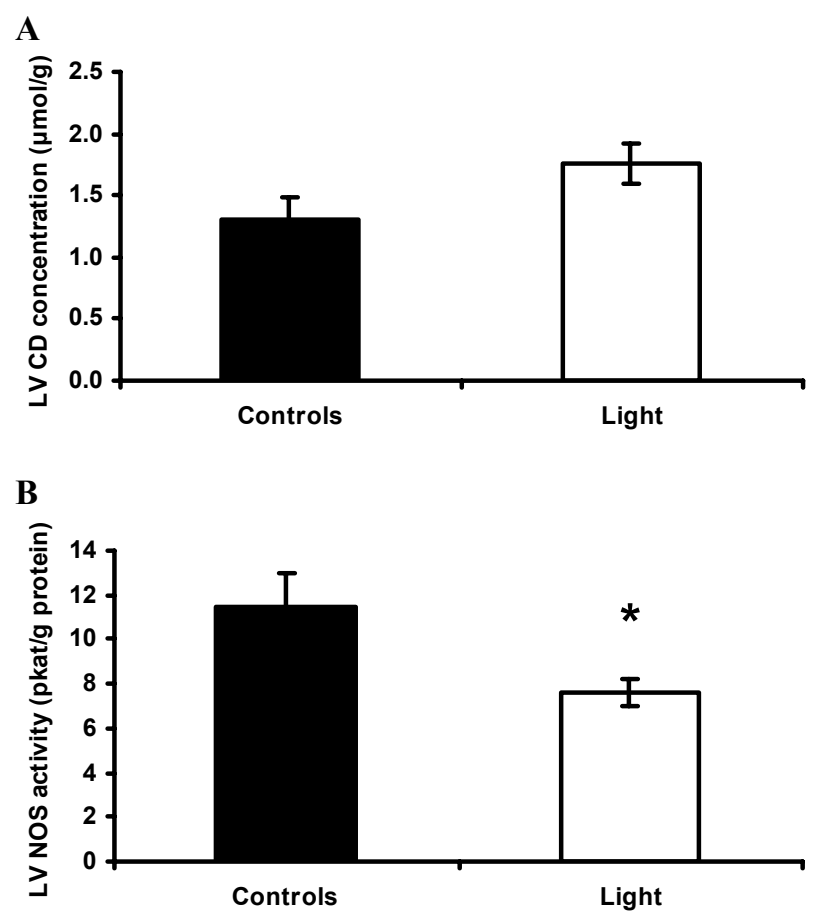

Fig. 5. The concentration of conjugated dienes, $C D(\mathbf{A})$ and the activity of NO-synthase, NOS (B) in the left ventricle (LV) of controls and rats exposed to continuous light (light) for 4 weeks. Data are means \pm SEM. $* \mathrm{p}<0.05$, Student t-test.

inhibition of NOS activity could, at least partially, explain the controversy in the effect of continuous light on functional recovery and on reperfusion arrhythmias. The addition of NOS inhibitor before ischemia increased the incidence and the duration of reperfusion arrhythmias (Kawahara et al. 2003, Pabla and Curtis 1995). However, NOS inhibition improved the recovery of coronary flow (Kawahara et al. 2003) and contractility (Naseem et al. 1995) and decreased the size of infarct area (Woolfson et al. 1995). Supposedly, long-term decrease of NOS activity in light-exposed rats could lead to saving substrates for NO-production that allow more rapid restoration of NOS activity after ischemia, which 
represents a strong stimulus for NO production (Depre et al. 1997). The subsequent coronary artery dilatation may enhance the recovery of coronary flow, myocardial contractility and relaxation. Nevertheless, more rapid changes in the myocardium caused by accelerated recovery of coronary flow could deteriorate electrical stability of the heart.

One should be aware, that lower melatonin levels levels may potentially result in attenuated antioxidant action of melatonin (Tan et al. 2000) and the lack of inhibitory effect of melatonin on glucocorticoid formation (Rebuffat et al. 1987), both facts being reported to inhibit NO formation (Maxwell, 2002) and decrease NOS expression (Maxwell 2002, Wallerath et al. 1999).

Our study has shown that continuous light exposure may modulate the outcome of cardiac ischemiareperfusion injury. However, further experiments are required to confirm whether observed changes are caused by decreased melatonin levels. These experiments should clarify whether observed effects are reversible by chronic melatonin treatment and to investigate correlations of above observed effects with glucocorticoid, melatonin and catecholamine plasma levels in rats exposed to continuous light.

We conclude that the exposure of rats to continuous light for 4 weeks improved ventricular functional recovery during reperfusion but increased the incidence, severity and duration of reperfusion arrhythmias in this group. In the left ventricle, the NOS activity was attenuated, but the concentration of CD was not significantly altered. Our results suggest that the modulation of cardiac response to $\mathrm{I} / \mathrm{R}$ by continuous light could be at least partially mediated by the attenuation of NO production.

\section{Acknowledgements}

This work was supported by the UK grant Nr. 226/2005, VEGA grants 1/3429/06, 2/6148/26, 2/5110/25, APVT grant 51-027404 and SP grant 51/0280900/0280901. The authors are very grateful to Dipl.-Ing. D. Pancza for his excellent technical assistance.

\section{References}

ALLEGRA M, REITER RJ, TAN DX, GENTILE C, TESORIERE L, LIVREA MA: The chemistry of melatonin's interaction with reactive species. J Pineal Res 34: 1-10, 2003.

BERNÁTOVÁ I, PECHÁŇOVÁ O, ŠIMKO F: Effect of captopril in L-NAME-induced hypertension on the rat myocardium, aorta, brain and kidney. Exp Physiol 84: 1095-1105, 1999.

BREDT DS, SNYDER SH: Isolation of nitric oxide synthetase, a calmodulin-requiring enzyme. Proc Natl Acad Sci USA 87: 682-685, 1990.

BRIAUD SA, ZHANG BL, SANNAJUST F: Continuous light exposure and sympathectomy suppress circadian rhythm of blood pressure in rats. J Cardiovasc Pharmacol Ther 9: 97-105, 2004.

BROWN GM, BAR-OR A, GROSSI D, KASHUR S, JOHANSON E, YIE SM: Urinary 6-sulphatoxylmelatonin, an index of pineal function in the rat. J Pineal Res 10: 141-147, 1991.

CUNNANE SC, MANKU MS, OKA M, HORROBIN DF: Enhanced vascular reactivity to various vasoconstrictor agents following pinealectomy in the rat: role of melatonin. Can J PhysiolPharmacol 58: 287-293, 1980.

DELIBAS N, TUZMEN N, YONDEN Z, ALTUNTAS I: Effect of functional pinealectomy on hippocampal lipid peroxidation, antioxidant enzymes and N-methyl-D-aspartate receptor subunits $2 \mathrm{~A}$ and $2 \mathrm{~B}$ in young and old rats. Neuro Endocrinol Lett 23: 345-350, 2002.

DEPRE C, FIERAIN L, HUE L: Activation of nitric oxide synthase by ischaemia in the perfused heart. Cardiovasc Res 33: 82-87, 1997.

GIROUARD H, DENAULT C, CHULAK C, DE CHAMPLAIN J: Treatment by n-acetylcysteine and melatonin increases cardiac baroreflex and improves antioxidant reserve. Am J Hypertens 17: 947-954, 2004.

HOLMES SW, SUGDEN D: The effect of melatonin on pinealectomy-induced hypertension in the rat. Br J Pharmacol 56: 360-361, 1976.

KAWAHARA K, TAKASE M, YAMAUCHI Y: Increased vulnerability to ischemia/reperfusion-induced ventricular tachyarrhythmias by pre-ischemic inhibition of nitric oxide synthase in isolated rat hearts. Cardiovasc Pathol 12: 49-56, 2003. 
KOGURE K, WATSON R, BUSTO R, ABE K: Potentiation of lipid peroxides by ischemia in rat brain. Neurochem Res 7: 437-453, 1982.

LEAF A, KANG JX: Prevention of cardiac sudden death by N-3 fatty acids: a review of the evidence. $J$ Intern Med 240: 5-12, 1996.

MAXWELL AJ: Mechanisms of dysfunction of the nitric oxide pathway in vascular diseases. Nitric Oxide 6: 101-124, 2002.

MEI YA, LEE PP, WEI H, ZHANG ZH, PANG SF: Melatonin and its analogs potentiate the nifedipine-sensitive highvoltage-activated calcium current in the chick embryonic heart cells. J Pineal Res 30: 13-21, 2001.

MIZRAK B, PARLAKPINAR H, ACET A, TURKOZ Y: Effects of pinealectomy and exogenous melatonin on rat hearts. Acta Histochem 106: 29-36, 2004.

NASEEM SA, KONTOS MC, RAO PS, JESSE RL, HESS ML, KUKREJA RC: Sustained inhibition of nitric oxide by $\mathrm{N}^{\mathrm{G}}$-nitro-L-arginine improves myocardial function following ischemia/reperfusion in isolated perfused rat heart. J Mol Cell Cardiol 27: 419-426, 1995.

PABLA R, CURTIS MJ: Effects of NO modulation on cardiac arrhythmias in the rat isolated heart. Circ Res 77: 984992, 1995.

PAULIS L', JANEGA P, PECHÁŇOVÁ O, ZICHA J, HOJNÁ S, VAŽAN R: Continuous light exposure protects rat heart against ischemia-reperfusion injury. Physiol Res 55: 2P, 2006.

REBUFFAT P, MAZZOCCHI G, GOTTARDO G, COI A, MENEGHELLI V, NUSSDORFER GG: An ultrastructural morphometric study of the effects of chronic melatonin administration on the zona fasciculata of rat adrenal cortex. J Submicrosc Cytol 19: 415-421, 1987.

REITER RJ: Melatonin: Lowering the high price of free radicals. News Physiol Sci 15: 246-250, 2000.

SAHNA E, OLMEZ E, ACET A: Effects of physiological and pharmacological concentrations of melatonin on ischemia-reperfusion arrhythmias in rats: can the incidence of sudden cardiac death be reduced? J Pineal Res 32: 194-198, 2002.

SAHNA E, PARLAKPINAR H, TURKOZ Y, ACET A: Protective effects of melatonin on myocardial ischemia/reperfusion induced infarct size and oxidative changes. Physiol Res 54: 491-495, 2005.

ŠIMKO F, PAULIS, L': Melatonin as a potential antihypertensive treatment. J Pineal Res 42: 319-322, 2007.

TAN DX, MANCHESTER LC, REITER RJ, QI WB, KARBOWNIK M, CALVO JR: Significance of melatonin in antioxidative defense system: reactions and products. Biol Signals Recept 9: 137-159, 2000.

VAŽAN R, STYK J, BÉDER I, PANCZA D: Effect of melatonin on the isolated heart in the standard perfusion conditions and in the conditions of calcium paradox. Gen Physiol Biophys 22: 41-50, 2003.

WALKER MJ, CURTIS MJ, HEARSE DJ, CAMPBELL RW, JANSE MJ, YELLON DM, COBBE SM, COKER SJ, HARNESS JB, HARRON DW: The Lambeth Conventions: guidelines for the study of arrhythmias in ischaemia infarction, and reperfusion. Cardiovasc Res 22: 447-455, 1988.

WALLERATH T, WITTE K, SCHAFER SC, SCHWARZ PM, PRELLWITZ W, WOHLFART P, KLEINERT H, LEHR HA, LEMMER B, FORSTERMANN U: Down-regulation of the expression of endothelial NO synthase is likely to contribute to glucocorticoid-mediated hypertension. Proc Natl Acad Sci USA 96: 13357-13362, 1999.

WOOLFSON RG, PATEL VC, NEILD GH, YELLON DM: Inhibition of nitric oxide synthesis reduces infarct size by an adenosine-dependent mechanism. Circulation 91: 1545-1551, 1995.

ZANOBONI A, ZANOBONI-MUCIACCIA W: Experimental hypertension in pinealectomized rats. Life Sci 6: 2327$2331,1967$.

\section{Corresponding author}

L. Paulis, Institute of Pathophysiology, School of Medicine, Comenius University, Sasinkova 4, 81108 Bratislava, Slovak Republic. Fax:+421-(0)2-59357601. E-mail: ludo@lfuk.sk 